\title{
Translanguaging in Primary Level ESL Classroom in India: An Exploratory Study
}

\author{
Lina Mukhopadhyay ${ }^{1, *}$ \\ ${ }^{1}$ The English \& Foreign Languages University, Hyderabad, India \\ *Correspondence: The English \& Foreign Languages University, Hyderabad, India. E-mail: \\ linamukhopadhyay@efluniversity.ac.in
}

Received: March 9, $2020 \quad$ Accepted: May 14, 2020 Online Published: July 14, 2020

doi:10.5430/ijelt.v7n2p1

URL: https://doi.org/10.5430/ijelt.v7n2p1

\begin{abstract}
In this paper, a series of ESL classroom observations of a teacher in an Indian primary level government run school are presented to show instances of concrete uses of translanguaging. The translanguaging practices were based on the inputs the teacher received from a training programme on using multilingual strategies to teach language and content. It is observed that the teacher applies translanguaging to clarify concepts using contrastive elaboration, to instruct students, practice discourse-based management, prepare students for classroom activities, and help them communicate. She also reflects upon her experience of translanguaging as she reports her plans to use students' L1 more systematically like drawing lexical and form based comparisons between Telugu, Hindi (L1s) and English (L2). Instances of translanguaging or fluid ways of communicating using two or three languages by this teacher and her experiences in using this approach help to validate the construct and to advance academic proficiency in students from low SES groups who would not otherwise comprehend the lessons if taught in the strict monolingual mode.
\end{abstract}

Keywords: code-switching, contrastive elaboration, discourse based management, ESL classroom, multilingual resources, translanguaging

\section{Introduction}

Primary education in government run Indian schools mostly have students who belong to the low SES strata and are disadvantaged by lack of monetary, infrastructure and educational resources at home (NSSO, 2014; Meghanathan, 2015; Barooah and Basarwal, 2017). These children have multilingual environment at home and in society. But the schools they attend either have regional language or English as the medium of instruction (EMI) and offer one or two other languages as subjects in keeping with the formulation of the 3-language policy for education (Pattanayak, 1981). The implementation of this policy and EMI is not without criticism (Petrovik \& Majumdar, 2010; Barooah \& Basarwal, 2017) because the system gives undue prominence to teaching of English either as a subject or as the MoI with the assumption that an early start would ensure better learning of the target language (Meghanathan, 2011). In addition to this, there is a lot of parental pressure and government moves to convert regional MoI schools to English MoI without preparing teachers or revising the pedagogical materials to suit learner needs (Coleman 2017; Brinkmann 2015). Most importantly the lack of overlap between children's home language and MoI poses an impediment in the path of language development and education because English is not a language that is available to the low SES students outside of class (Mukherjee \& Vasantha, 2002). Consequently, this leads to low learning outcomes and this has been widely reported in large-scale school surveys in the country (Pratham, 2017; Erling et al., 2016).

In Indian schools that practice EMI, teachers and students are multilingual, but the teachers are neither trained nor encouraged to use multilingual repertoire of the students in a systematic and planned manner by way of transferring linguistic cognitive aspects of a language students know well (L1) to a second or a newly developing language (English) (Cummins, 2007). In many cases even if teachers try to utilize students' L1s, it is mostly at the lexical level or a mere word-to-word translation to help them get on with content but hardly ever engage in the meaning making process or multilingual communication. The fact that classroom research on the use of multilingual resources to learn 
the target language and academic concepts have been found to be very useful for imparting school education in the Indian multilingual context (Durairajan, 2017; Anderson \& Lightfoot, 2018; Canagarajah, 2013; Garcia and Wei, 2014; Tsimpli, 2019) gets a mention in the national language policies (NEP 2019); but the intent to implement the strategies are largely overlooked by other stakeholders of learning such as curriculum developers and administrators for in-service teacher training programmes in India. Therefore, this paper in a novel approach documents the benefits of systematically using multilingual resources in Indian primary education, even though the state policy expects EMI to be practiced in a monolingual manner. The possibility of using multilingual resources to develop knowledge of the language of instruction and understanding of content knowledge through that new language was made possible due to a longitudinal project 'MultiLiLa' described below.

\subsection{The Multilila Project}

The MultiLiLa research project is UK ESRC funded four year long project initiated by the University of Cambridge in collaboration with Indian and UK partners to study the learning outcomes of bi/multilingual grade four and five students from low SES background and studying under challenging contexts across three sites - Delhi, Hyderabad and Patna. The learning outcomes have been studied with respect to literacy, language, cognitive abilities and mathematics in regional MoI and English to understand if children who have an overlap between their home language and MoI enjoy an advantage over the ones who do not. Key findings of this project as learning outcomes is that children who are bilinguals at home and have an MoI overlap with home language, experience age appropriate general intelligence scores as measured on raven progressive matrices (Tsimpli et al., 2020) and show oral narrative abilities higher than literacy scores when measured in MoI (Mukhopadhyay et al., in press).

In the project, educational factors impacting children's learning was measured through

(i) classroom observations of English and mathematics lessons and

(ii) questionnaires to collect teacher opinion on use of EMI.

These explorations were done to better understand how do teachers transact knowledge in class with a multilingual group of students who aspire to learn English. Classroom observation analysis across the sites showed that language mixing happened within a range of $43 \%$ to $60 \%$ in both English and content classes, with more mixing instances being observed during the mathematics lessons (Lightfoot et al. submitted). Though teachers were observed to use quite a few pedagogical practices ranging from read aloud to solving problems and having discussion with students, the extent to which they were mixing the languages for structured planned pedagogic inputs to scaffold learning in the target language was not too clear.

Based on the findings of classroom observations from MultiLiLa, a 6-month training became the second part of the project where in-service teacher awareness was raised through a series of demonstration that focused on the uses of translanguaging and its possible benefits. In this paper, the experiences and use of multilingual resources as practiced by one teacher who participated in the training will be reported. Her instances of use of translanguaging will (a) validate the construct and (b) help to understand how this approach can be used for pedagogic inputs in a principled and concrete manner.

\subsection{Translanguaging}

Translanguaging or 'trawsieithu' as one instance of a structured multilingual pedagogic practice emerged as an approach to bilingual education where students in bilingual Welsh/English classrooms were encouraged to alternate languages to communicate in oral and written forms (Williams, 1994, as cited in Garcia \& Lin, 2016: p1). Since then this pedagogical practice has been theoretically acknowledged and researched upon. There are multiple references of the positive impact of such research in several multilingual contexts as examined in the works of Canagarajah (2011), Garcia (2009, 2011), Garcia \& Lin (2016), Garcia \& Wei (2014), Wei (2011), Hornberger \& Link (2012), and Lewis, Jones \& Baker $(2012,2013)$ to name a few. However, use of translanguaging for pedagogic purposes has also met with resistance from practitioners of direct and monolingual methods of teaching languages as they have felt that this fluid interaction using two or more languages would make the target language learning process 'laborious' and 'contaminated'. Interestingly the usefulness of this method and its pedagogical validity in multilingual contexts and in linguistic minority student communities has far outweighed its limitations and criticisms over the last four decades (Coleman, 2017; Tsimpli et al., 2020).

Furthermore, the definition of the term translanguaging has not been without problems, as other competing terms already exist like translation, code switching and code mixing. The distinctiveness and validity of translanguaging as an educational practice has been well brought out by Garcia \& Lin (2016: p.2): 
...translanguaging is linked to the study of code switching in education in that it also disrupts the traditional isolation of languages in language teaching and learning. Throughout the world, code switching, understood as the going back and forth from one language to another, has been used by teachers to scaffold the teaching of additional languages. Although this practice has not been generally legitimized in language-teaching scholarship, teachers engage in code switching on a day-to-day basis.

Interestingly, before the western school space started using of this term 'translanguaging', the use of multiple languages to foster communication remained a natural choice in multilinguals across the world, and most certainly in India. Some researchers in India have documented instances and success of using this practice in the recent years (Anderson, 2018, Anderson and Lightfoot, 2018, Chimirala, 2017, Durairajan, 2017, Manocha \& Panda, 2017). Yet a lot of it yet remains to be represented based on Indian classroom practices. To use this fluid medium of communication as an alternative to the strict monolingual and direct method of instruction in schools, the primary place of contact for young students, is by no means easy. Moreover it will not gain acceptance as a natural classroom phenomena unless the language policy of the nation-state by understanding its importance accept and implement it. Therefore this paper strongly argues for the need of this practice in primary level education as a way of extending what children experience at home to their classrooms so that learning happens in a mediated and comprehensible manner.

In this paper, the construct of translanguaging will be seen as all instances of code-switching and translation as systematic, conscious and planned ways of communication in the classroom for purposes of learning concepts as well as the target language, and for teacher-student negotiation for meaning and communication. This multidimensional construct of translanguaging would thus be open to accommodating the needs of both content and language teachers in the EMI context.

\section{The Study}

This section will refer to the methodological aspects of the study like type of research, research questions, participants' profile, and data collection tools, phases and method.

\subsection{Type of Research}

This is an exploratory study about a teacher and her translanguaging practices through L1s and English for a variety of linguistic purposes such as concept clarification and practicing lexis and fluency activities. Her classroom lessons will show her integration of the translingual practices post her experiences at the training workshop of MultiLiLa. After each lesson, she has expresseed her views through semi-structured interviews. So the study revolves around an in-depth exploration of this teacher's understanding of the translanguaging approach and its application in class in a systematic and planned manner and also captures her thoughts on the usefulness of this approach and why it works for her students.

Many studies conducted in India mention the use of translanguaging. There are two papers on meta analysis of translanguaging practices and teacher attitudes in Indian classrooms across different SES groups by Anderson \& Lightfoot 2018 and Anderson 2018. But an in-depth qualitative analysis of classroom sessions and teacher voices has not been attempted before to show what can constitute concrete steps to practice this approach in class, especially for beginners level learners who are young and come from disadvantaged backgrounds owing to their parents' low income and education level coupled with lack of literacy practices at home. So in this paper makes a unique attempt to document the uses of translanguaging and teacher opinion on its usefulness.

\subsection{Research Questions}

This paper attempts to answer two research questions:

1. What are the purposes of using translanguaging in the ESL classroom?

2. What is the teacher role in use of translanguaging?

\subsection{Participant Profile}

The teacher Anita(Note 1) who participated in this study had been working in a government-run low cost primary school in urban Hyderabad, capital city of Telangana a state in the south of India. She appeared to be well prepared for her classes and participated in the workshop with enthusiasm and engagement. Her spoken and written fluency was balanced in Telugu and English and she could also speak in Hindi (a second official language of India) and use 
Lambadi (a tribal language of migrant workers) for social communication with her students. Her knowledge of language teaching methodologies were up-to-date and she was aware of the benefits of using task based approach in ESL teaching.

The class where Anita's lessons were observed comprised of 39 ESL learners ( 25 female; 14 male) aged between 7 and 11 years(Note 2), enrolled in grade four and with three to four years of exposure to English as a subject and a few months of exposure to the language as MoI. At the time of the study, when Anita's school had just transitioned to the EMI setup, she had the opportunity to attend the training and learn how to better implement the translanguaging approach as she mentions in one of the interviews interview reported in section 3.2 below.

\subsection{Data Collection Tools}

The data was collected using the following tools:

Classroom observation template and notes

As a part of the MultiLila project to observe the classroom environment, a tool was designed using scales with indicators (see Tsimpli et al 2019 for details). The same tool was used for this paper. The scales document a wide array of practices and multilingual approaches used in the classroom at the time of the observation. The tool consists of five sections: 1 . Teaching environment; 2 . Observation of teacher activity and child response; 3 . Teaching content and strategies; 4. Teaching practice and 5. Record of good practices. Languages used by teacher and students could be recorded for every five-minute interval of each 30-minute lesson. In addition to this, qualitative notes documenting classroom interactions and focus and design of language activities, were also maintained.

\section{(ii) Teacher semi-structured interviews}

After the training programme and at end of each lesson a semi structured interview was conducted over phone. Open-ended questions were used to document teacher awareness, her plans to integrate translanguaging practices and the kind of feedback she required to organize her future lessons (for details refer to Mathew et al. submitted).

\subsection{Background of the Study and Procedure}

In the back drop of examining educational variables in learning outcomes of school skills in low SES group Indian children in the MultiLiLa project, classroom practices showed that teachers alternated between languages for pedagogic purposes; but principled and planned use of this approach was not to be found. So in the second phase of the project a teacher training programme on uses of multilingual resources in a principled manner was conducted. 22 primary school level teachers who expressed interest participated in it. The training was conducted as part of an impact study of the MultiLiLa project and in collaboration with the University of Cambridge, EFL-U and British Council, India division (for details refer Mathew et al. submitted). From the group, five teachers agreed to prepare lessons incorporating uses of translanguaging in English and content classrooms. Anita was one of these five teachers who was observed for a series of three ESL lessons. In these lessons she planned, used, and most importantly reflected upon her practice of translanguaging. The observations were interspersed with Anita's regular classes and in all she was observed for four months post the training.

This study is going to be reported in two parts - one, demonstration of use of teacher-directed translanguaging as found from the three ESL lessons; and two, analysis of semi-structured interviews conducted soon after the training, and following each of her lessons.

\subsection{Method of Data Analysis}

Classroom observations were collected based on quantifying frequency of occurrences of language mixing and translanguaging in the teacher and the students. This was coded in the questionnaire template and later converted to percentage of frequency for analysis.

In addition to this, classroom interactions and teacher's responses on the interviews were transcribed as utterances(Note 3 ) and checked for inter rater coding at a significant correlation level of $r=0.87, p<0.05$.

In order to analyze the transcribed data for instances of translanguaging during the classroom sessions the following parameters were used:

$\checkmark \quad$ to highlight instances of translanguaging and the corresponding purposes it is used for;

$\checkmark$ to present teacher-student interactions and the various functions they are used for;

$\checkmark \quad$ to focus on the language teaching methodology and aids used

The qualitative model of analysis adapted was a combination of the following: 
- classroom instances of translanguaging as using simultaneous features of two languages for (i) contrastive elaboration; (ii) practice of two languages simultaneously in reading or writing or both; (iii) discourse based management; and for (iv) self identity with languages (Garcia 2015, 2016; Makalela 2015);

- negotiation of meaning between interlocutors (teacher and students) in the form of comprehension checks, clarification requests and confirmation checks (Ortega 2009: pp. 61-71)

The above features were analyzed based on the classroom notes and teacher interview transcripts.

\section{Findings}

In this section the findings of the exploratory study are presented to answer the two research questions.

\subsection{Frequency of Translanguaging in ESL Classroom}

In all the 3 lessons observed, the use of languages were in the following proportion for the teacher and the students are as reported in Figures 1 and 2:

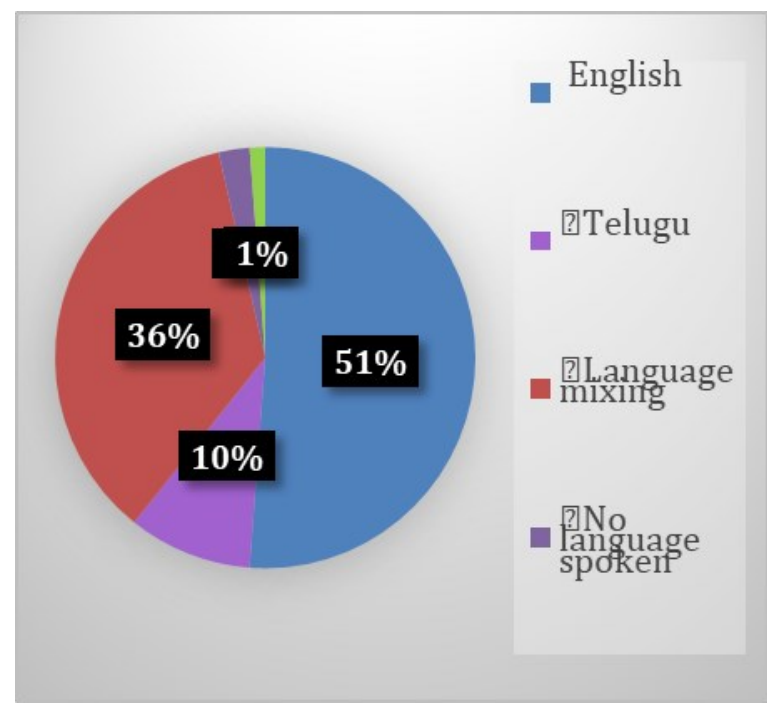

Figure 1. Teacher's Use of Languages

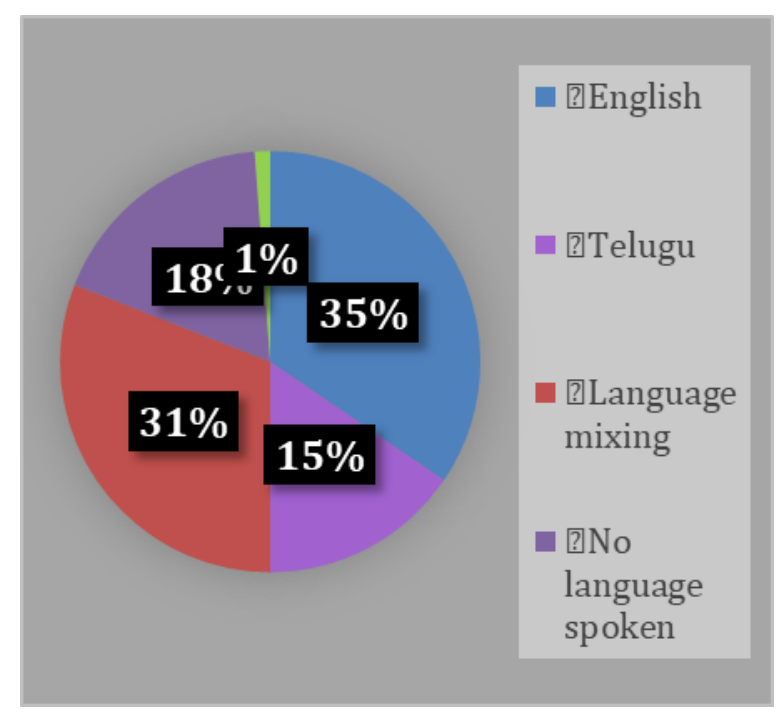

Figure 2. Students' Use of Languages

The instances of mixing Telugu, Hindi and English were found to be quite fluent in case of the teacher as she used a friendly conversational tone to support the students in practicing English interspersed with their home languages. For instance Telugu and Hindi were used predominantly for scaffolding learning with specific target vocabulary in English. Though the teacher opined that she would be satisfied to use more English in class but she is aware that her students would need scaffolding through their home languages and for this reason she is open to using multilingual resources.

The learners were found to use English with support of other home languages as Telugu, Hindi and Lambadi, though there are parts of the lesson where they used no language. This was because these parts had teacher explanations, which did not necessitate any conversation.

\subsection{Translanguaging to Learn Specific Language Aspects}

In this section through a few instances of the language activities that the teacher engages with, we look at teacher-student interactions as instances of translanguaging for pedagogical purposes.

In the first lesson, Anita began her class by asking the students in a mix of Telugu and English to open the English textbook, unit 7, titled 'I was bad at cricket'. Referring to a picture in the textbook she enquired the following: 


\subsubsection{Interaction for Meaning Negotiation}

T: Can you see a picture? What are some of the words you can use to describe the pictures?

SS: $\quad$ happy, Cricket, play, cheerful ...

$\mathrm{T}$ : $\quad$...She asks for a few synonyms of the words - /happy = anandam, santosham/

T: $\quad$ Okay from the picture we will now practice some action words. Who will help us do this activity?" (mix of Telugu and English)

SS: $\quad$ They look at each other, and one girl named Srika volunteers to do the activity by raising her hand.

T: $\quad$ Is it okay that Srika will guide you? (in English)

While giving instructions the teacher kept using related words and phrases from Telugu to help the students connect to vocabulary to be used for this lesson. With a series of comprehension and confirmation checks she helped the children notice lexical synonyms across Telugu and English.

\subsubsection{Activity for Vocabulary}

Later she brought out mini cut outs of people playing football, tennis, boxing and asked the students "to observe the difference" and give the names of the different sporting persons.

a. Cut out of a cricket player

T: Let us now look at the picture in my hand. Which game is played? (shows pic of a batsman)

SS: Cricket.

T: How do you know that?

SS: The bat.

T: Now I will show you some more pictures of games. You tell me which sports or action you can see.

b. Cut out of a football player:

$\mathrm{T}$ : What is this picture?

SS: Football

T: How could you say that? By jumping/skipping/standing?

SS: By looking at the feet.

c. Cut out of a boxer:

T: Name of the player?

SS: Sania Mirza?

T: Is this Sania Mirza? Where have you seen her? In India?

SS: In posters.

T: Okay, seen her in posters. She is Mary Kom.

Anita used Telugu as and when required along with English as the primary language of instruction; the mini conversations given above were in English. Her use of translangauging at this stage was still mainly to better communicate with the students and to help them notice a few words/phrases.

\subsubsection{Activity for Grammar Through Reading}

In the same lesson after brainstorming with the students about naming (common nouns) and action (verbs of motion) words, Anita asked them to get into smaller groups of five or six, read a short text and underline the action words.

For this activity she gave 10-15 minutes and then from each group one student was invited to write their list on the board. This instruction Anita presented in a bilingual manner so that the students knew what the teacher expected them to do in the next 15 minutes of the lesson.

The class, divided into five groups, came up with responses as presented in Table 1: 
Table 1. Listing Actions Words

\begin{tabular}{lllll}
\hline Group 1 & Group 2 & Group 3 & Group 4 & Group 5 \\
\hline missed & dropped & seemed & watched & looked \\
playing & tried & asked & & \\
*evening & slowly & *grooned (=groaned) & & \\
& & & & \\
\end{tabular}

Here are a few observations about the responses:

Many of the students had generalized the past tense marker/ed/ and /ing/ to identify action words form the text. Although this analysis helped them pick action words well, but there were a few overgeneralization errors as follows:

(i) the verb 'seemed' is a mental category verb and not an action word;

(ii) one student identified the present progressive marker /ing/ to identify action words and has listed 'evening' as an action word. This is an overgeneralization error where students are found to use the strategy of tense morphemes (e.g. /ing/) to identify action words - so using a grammatical category for vocabulary recognition. The teacher gave feedback that this is an exception and 'evening' is a noun. So along with knowledge of morphological markers, students need a morpheme level analysis to identify which are root words (e.g., evening) and which are morphologically inflected words (e.g., miss $\rightarrow$ missed, missing). Thus, mere presence of a marker may not be sufficient to categorize words into action words.

Another interesting point noted is that one child had also put down a word like 'slowly' which is a manner of action word or an adverb, but rightly within the category of action words. So this indicated that the students were going beyond what the teacher expected them to do, identify action words or verbs; they were also associating other words that represent 'action' with help of adverbs. This is an instance of learning: here students show an ability to extend their learning to related concepts and willingness to explore a wider set of vocabulary.

Anita gave feedback on the board work activity by saying that there is something called 'language consciousness' or the brain hints if a word does not exist in the language. She said this with reference to the spelling of the word 'groaned' misspelt by a student as 'grooned'. She also summarized that two parts of speech can be considered in action words - verbs with tense markers and adverbs indicating manner of movement (slowly, fast etc). Some of her form-based explanation was interspersed with Telugu and Hindi along with English.

In a second lesson Anita attempted to bring in translanguaging practices by using English interspersed with Telugu and Hindi in her interactions with students to make them practice social function like explaining daily routine.

\subsubsection{Activity for Oral Communication}

A teacher-student pair activity was conducted to help students practice oral fluency in English interspersed with Telugu and Hindi.

\begin{tabular}{|c|c|}
\hline $\mathrm{T}$ : & $\begin{array}{l}\text { What work did you do at home ? Ghar pe kyakaamkiya?Cheppu..Intloemi chesavu, tell me. [tell } \\
\text { me...in-home what you do-past](note 4) }\end{array}$ \\
\hline S1: & Nenu Amma ki vessels clean cheydam lo help chesanu. [I to-mother vessels clean to do in help do-past] \\
\hline T: & $\begin{array}{l}\text { Do you do it every day? Yes? When you do every day then say -" help } \\
\text { chestava" [help do] ante "I help Amma". If you did only yesterday then say "help } \\
\text { (ante helped) [help do-past = helped] }\end{array}$ \\
\hline S2: & $\begin{array}{l}\text { Nenu ground la ball aadenu. I played ball. [I in ground ball play-past.] (la=in; Telangana colloquial use } \\
\text { instead of 'lo' that is standard variety] }\end{array}$ \\
\hline S3: & Nenu cook chestha. Cook karne ko help kiya. [T: I cook do] [H: Cook do-inf for help do-past] \\
\hline S4: & Main`swimming ku gaya... Tairneku [Dakkhini: I swimming to go-past] \\
\hline
\end{tabular}

Anita seems to be aware of the use of multilingual practices where she allows students to use their stronger language to demonstrate the use of activities (as action verb phrases) in daily life in L2 (English) and yet use Telugu or Hindi to converse. The teacher-student interaction can be seen as an instance of breaking away from the usual initiation-response-evaluation pattern to one where students are initiating moves. Further there is a natural mix of 
Telugu/Hindi and English that makes learning more meaningful and teacher acknowledges the languages multilingual students bring to the classroom.

\subsubsection{Activity for Semantic Classification}

In the third and last lesson, Anita focused on classifying words into broader sematic categories. To check their understanding of the meaning and to provide them with definitions for English words when they were unsure, Anita used a mix of Telugu, Hindi and English. The word classification activity was done in small groups.

In Figure 3 below a classification of English words into broader semantic categories (e.g., vehicles, familial terms) with their lexical equivalents in Telugu and Hindi was prepared by the students as a group activity. This was then put up as a wall journal for everybody to learn from each other's inputs.

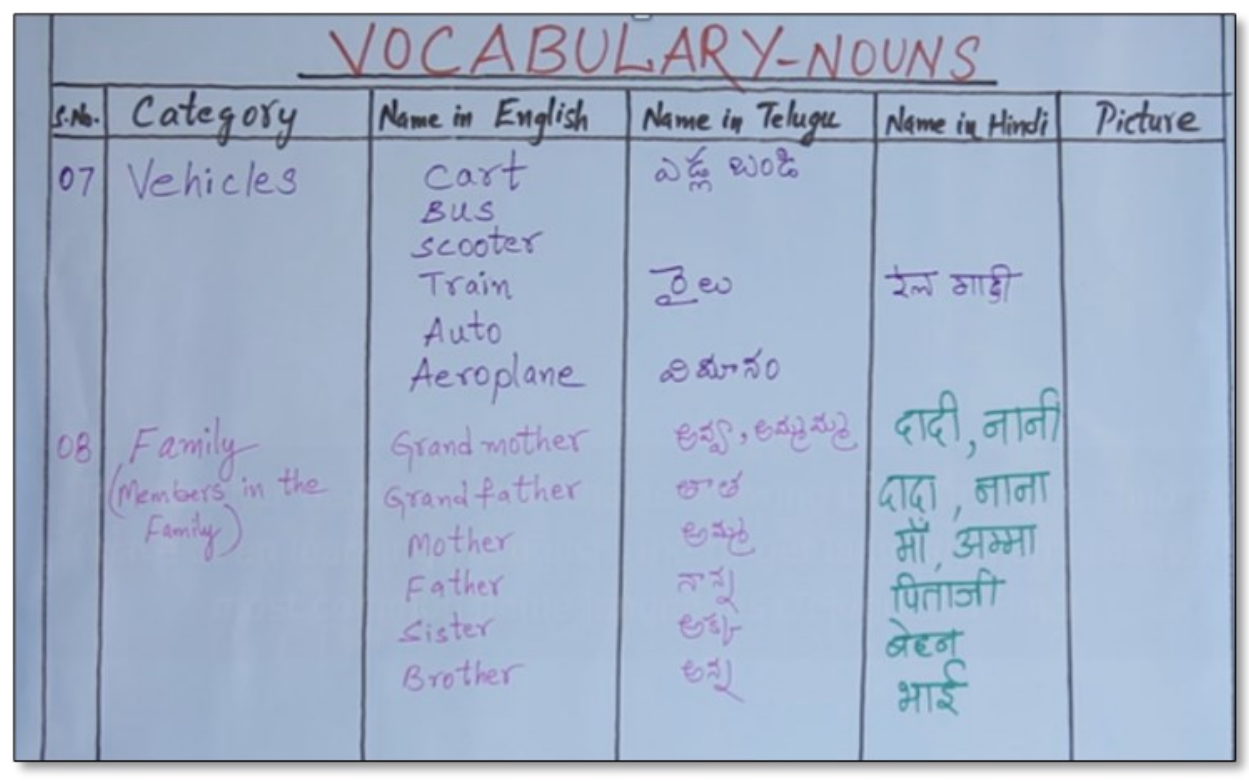

Figure 3. Semantic Classification \& Translanguaging

Some of the students in this class seemed to struggle with producing single words, while others had some confidence in producing longer sentences. But this kind of active scaffold is likely to draw students' attention towards minute linguistic features which otherwise would have gone unnoticed and learning opportunities would have been missed (Shephard-Carey 2019).

\subsection{Teacher Opinion and Engagement on Translanguaging}

In a series of semi structured interviews, Anita's engagement with the method of translanguaging and its application in class were studied. Her responses were an indication of her experience and attitude in adapting this method for her students.

\subsubsection{Awareness about Student Needs}

The first set of responses was obtained soon after the training when Anita was in the process of planning her first lesson to be observed. At this stage she expressed her awareness about her students' multilingual backgrounds and the need to use translanguaging:

\section{Extract 1}

Here we have children from different backgrounds. They speak different languages. Majorly they are from Telugu-speaking background but still we have a tribal community called Lambadi where they speak the Lambadi language. A few are from the Muslim community. They speak Urdu at home. So here we do interact with them in Hindi. Then we have very few Kannada people because they migrated from nearby Karnataka [...] but I don't know Kannada and other teachers also don't know Kannada, but majorly Hindi, we take the help of Hindi. That's how we use all three different languages. 
Anita described the linguistic diversity present in her school and that Hindi is used as a link language for those students who do not use Telugu or English at home.

When enquired what did she benefit from attending the workshop, she replied:

Extract 2

My main takeaways from the workshop are the use of terminology regarding the ML which I am already into practice but was unaware of the terms. Now I can easily include that terminology in my lesson plans.

After the training, Anita got a few weeks to plan and strategize the use of translanguaging in her classes. Extract 2 is an example of her planning mechanism when she was interviewed to know if she had integrated the inputs from the training into her classroom practices.

\section{$\underline{\text { Extract } 3}$}

Yes, when I prepared my lesson plans I made a mental note of where I am going to use Telugu and Hindi, which earlier to the workshop I never did. It used to be a spontaneous input. I feel that planning the multilingual inputs gives a better opportunity to anticipate the problems students might face in understanding the concepts to be taught and their learning needs.

Anita's responses again reiterates the fact that she has awareness and tries to better accommodate student needs and help them learn through the translanguaging approach.

\subsubsection{Teacher Engagement with Translanguaging}

After her first lesson was over, Anita expressed that thinking about the concept of translanguaging, which she had received training two weeks prior to the observation, made her use Telugu in the English lesson more consciously and choose which purposes to use it for.

Her main intention was to use the students' L1 to clarify concepts so that they could better communicate in English:

\section{Extract 4}

The training inputs has made me realise how should we pre plan or how should we have a strategy before we go for class, how can we implement L1 use as a part of our lesson plan."

Anita was able to reflect on the usefulness of planning to use translanguaging in class systematically and her perception of student benefits seemed to be aligned to her lesson goals:

\section{Extract 5}

“...assigning the specific time for the use of other languages was planned meticulously. I feel that learners were more comfortable with that. I always used Telugu and Hindi in my classes but by the planning to use it I have achieved more responses from the student and display of better understanding by them."

\subsubsection{Teacher Reflection as Professional Development}

Anita as a result of the training and the positive classroom observation experience seemed to be more open to trying out translanguaging in her future lessons. This is an evidence of an attempt at professional development to use multilingual resources:

\section{Extract 6}

As I said already I am already into ML, all the government institutions are like this...How this helped me is, first its professional enrichment and I am not at all proud to say that our proactiveness also matters- where I am ready to learn and change or not- that made me come there and attend the workshop. The interaction with the participants and the various subject experts has made me realize the importance of L1 use in class. Next week when I actually do this in the class I should be better able to give you more examples of the challenges I may have doing this - my students' interaction in that regard.

After her last lesson Anita was interviewed for one final round where she spoke about her activities and how she has explored the translanguaging approach and shared it with her colleagues:

Extract 7 
From whatever we learnt in the workshop and the lessons where I was observed, I can now write better training material for the training that I have been doing for last month. I trained 30 teachers and then 220 teachers in my Mandal. I still have to learn and experiment with this, I mean multilanguage inputs. Because it's basically more about that, with this oral instructions from the government have only English medium in our schools. The schools were Telugu medium and now they turned into English medium. The teachers were struggling to use only English in the class, so mother tongue and common language has to be used. That was what I could share with them from what I learnt from the training workshop.

In sum, Anita's comments give us evidence that for the translanguaging practices to be effective and well aligned to the unit taught and student needs, teachers need to be 'engaged' with the concept right from the stage of preparation, to classroom use, and during post lesson reflections. All these stages can further help in building students' estimate of performances over time.

\section{Discussion}

Throughout the findings section, various instances of use of translanguaging as practiced by the teacher along with her reflections on the usefulness of the practice are presented.

\subsection{RQ1: Purposes of Using Translanguaging: Contrastive Elaboration \& Fluency}

Anita was well prepared for her lessons and her attempts to teach vocabulary along with grammar and give students practice with help of a series of activities has worked well with the students. Her lessons were a good example of using the communicative mode as well as translanguaging to help students focus on concept learning and noticing lexical and grammatical aspects of English.

Throughout her lessons, Anita used Telugu and Hindi along with English to give instructions to the students and prepare them to do a series of activities listed in section 3.2. Most of her translanguaging happened to fulfill language functions of instruction, explanation, and group feedback to ensure that students are able to comprehend her instructions and carry out the tasks well.

She also used translanguaging to draw students' attention to lexical equivalents in Telugu, Hindi and English action words and words under each semantic category. Furthermore, translanguaging helped her compare and contrast grammatical aspects like change in word forms to convert words from present to past tense and so on.

Some of the common uses of translanguaging were for the following:

(i) for concept clarification and elaboration through contrastive elaboration (activities for vocabulary, semantic classification and extract 3),

(ii) fluency practices across two languages (MoI and students' L1) (activities for communication and semantic classification and extract $3 \& 5)$ and

(iii) discourse based management: for ease of communication and spread of the approach amongst colleagues (interaction for meaning negotiation and extract 7).

\subsection{RQ2: Teacher Role: Impact of Awareness and Preparedness}

From examples in section 3.2 and 3.3, it can be observed that the translanguaging practices have been teacher directed. But the teacher has played a crucial role in transforming pedagogy to enable communication and learning that most students feel comfortable with because they are allowed to code-switch between languages, as they would have done in a naturalistic context outside class (Garcia \& Wei, 2014). The translanguaging practices presented in this paper were to demonstrate one of the findings from the MultiLiLa project classroom observations that teachers use multiple languages for meaning transaction and creating opportunities for students to communicate and express their understanding. While it easy to theorize that there are 'rules' and standard practices that are followed with code-switching or language mixing in day-to-day life which support meaning making (Wei, 2017), but perhaps what is not made clear to many teachers is what those practices should look like in the classroom to ensure appropriate scaffolding and optimum learning. Therefore this paper has demonstrated in a novel manner some concrete examples to plan and adopt the translanguaging approach in primary level classrooms for developing different linguistic aspects. This approach can be successfully implemented keeping in mind the multilingual repertoire of the teacher and students. Done in such a constructive spirit, translanguaging practices can truly act as a scaffolding device to acquire a new language (L2). 
Though Anita attempted to use translanguaging, she used it only at the oral level and not for print purposes. Also there were no activities planned with two language inputs or outputs. She had rather made a mental plan to use Telugu inputs with English as a translanguaging practice during her activities. Overall Anita could be seen to use a few of the multilingual strategies that she received training which might have helped her break away from a teacher centered class to more learner centered one (Clarke, 2003) and acknowledge students' linguistic resources from their L1s.

Anita had participated in the first phase of MultiLiLa and came back for the training programme and subsequently agreed to be observed and participate in reflection activities. All of this shows high willingness on part of the teacher to reflect and adopt new strategies. Teacher attitude therefore played a big role in the success of using the translanguaging approach in her classes. Her awareness that this is a useful approach and therefore actively engage with it, plan to use it and gain satisfaction as a result of using it with her students is shown through the seven extracts. In all it shows that when teacher attitude is positive towards this approach it helps her to implement it in class in a systematic and principled manner.

\section{Conclusion}

In the forceful words of Garcia on role of translanguaging in education: just as multilingualism helps us makes sense of the world so also educating bi/multilingual children using translanguaging paves the way for dynamic bilingualism (2009: pp. 151-153). Likewise this paper has demonstrated how a teacher in a planned manner and with student needs in mind can use translanguaging to create learning opportunities. But there still remain a few limitations and some ideas for recommendations for pedagogy and research as discussed below.

\subsection{Limitations}

This is an exploratory study with one participant teacher's use of translanguaging practices in her ESL classes and her views on the usefulness of this approach. While the in-depth qualitative content analysis of classroom observations and teacher reflections has given us a good understanding of some concrete steps to initiate and explore this approach, much needs to done in future. The study has not been able to show any growth in students' language because this was outside the preview of this paper. This is a significant area of research where translanguaging practices can be the independent variable and its impact on students' inter language development and language skills be treated as dependent variables and their links can be studied. Another aspect that can be further explored is to take up large scale government run projects which can look at teacher practices and voices in larger numbers by attempting a frequency analysis based on classroom practices and qualifying it with examples as presented in this study. Such wide spread concrete practices would help teachers get ideas how to use the approach in a creative and interesting manner to create conditions for inclusive education and help to validate the usefulness of the construct in the Indian context.

\subsection{Recommendations}

Overall, this exploratory study of a teacher's attempts at planning, and actual use of translanguaging in the English classroom shows that if conceptualized and planned effectively the practice can be beneficial for students who would not have comprehended the lessons if the teacher strictly followed the direct monolingual method (Arthur \& Martin, 2005; Durairajan, 2017; Canagarajah, 2011a). Therefore, it is important that teachers are able to integrate the steps of translanguaging into their lesson or action plans (refer to Appendix for an action plan). Teachers should also be able to reflect on the efficacy of the approach as Anita did in the post lesson interviews. They can create a journal with logs of their own growth in using this approach. Furthermore, teachers need to document student growth as a result of using this approach by means of informal formative assessment so that no student misses an opportunity to learn (Shephard-Carey 2019). Specific skill and form-based activities where translanguaging steps can be incorporated needs to be designed and shared with other colleagues as Anita attempts by the end of her third lesson (see extract 7) (Garcia \& Hesson, 2015: pp. 232-233). Done systematically, the practice of translanguaging can be a source of satisfaction and motivation for ESL teachers to perform better. In conclusion translanguaging can support the learning of content and languages, acknowledge students' L1 resources and thereby validate it as an effective pedagogical tool. 


\section{Acknowledgement}

I would like to express my sincere thanks to my colleagues on the training team - the Principal Investigator, Professor Ianthi Maria Tsimpli, and two other trainers Professor Rama Mathew, and Ms. Amy Lightfoot for their support on the training, classroom observations and filming, the two research associates Ms. Vrishali Ingle and Ms. Radhika Chebrol for their assistance in classroom observation planning and execution. I also extend my thanks to the participating schools and their teachers and students.

\section{Funding}

The funding for the impact training was awarded to the University of Cambridge; RG99354 under GCRF Global Impact Acceleration Account (GIAA) Impact Fund titled "Harnessing multilingualism in primary school classrooms in India: professional development and training for teachers in government schools", from 01/12/2018 to 31/03/2019.

Conflict of interest: There was no conflict of interest.

\section{References}

Anderson, J., \& Lightfoot, A. (2018). Translanguaging in English Language Classrooms in India: Current perceptions and future possibilities. International education of bilingual education and bilingualism. https://doi.org/10.1080/13670050.2018.1548558

Anderson, J. (2018). Reimagining English Language Learners from a Translingual Perspective. ELT Journal, 72(1), 26-37. https://doi.org/10.1093/elt/ccx029

Arthur, J., \& Martin, P. (2006). Accomplishing lessons in postcolonial classrooms: Comparative perspectives from Botswana and Brunei Darussalam. Comparative Education, 42, 177-202.

Barooah, Vani. K., \& Nidhi Basharwal. (2017). English as a Medium of Instruction in Indian Education Inequality of Access to Educational Opportunties. CPRGE Research Papers 7. Centre for Policy Research in Higher Education. National University of Educational Planning and Administration. New Delhi.

Brinkmann, S. (2015). Learner-centred education reforms in India: The missing piece of teachers' beliefs. Policy Futures in Education, 13(3), 342-359.

Canagarajah, S. (2011a). Codemeshing in academic writing: Identifying teachable strategies of translanguaging. The Modern Language Journal, 95, 401-417.

Canagarajah, S. (2011b). Translanguaging in the classroom: Emerging issues for research and pedagogy. In L. Wei (Ed.), Applied linguistics review (Vol. 2, pp. 1-27). Berlin: De Gruyter Mouton.

Canagarajah, S. (2013). Translingual Practice. New York, NY: Routledge.

Chimirala, U. M. (2017). Teachers' 'Other' Language Preferences: A Study of the Monolingual Mindset in the Classroom. In H. Coleman (Ed.), Multilingualisms and Development: Selected Proceedings of the 11th Language and Development Conference, New Delhi, India (pp. 151-168). London: British Council.

Clarke, P. (2001). Teaching and learning: The culture of pedagogy. New Delhi: Sage Publications.

Clarke, P. (2003). Culture and Classroom Reform: the case of the District Primary Education Project, India. Comparative Education, 39(1), 27-44.

Coleman, H. (2017). Development and Multilingualism: An Introduction. In Coleman, H. (Ed.), Multilingualisms and Development: Selected Proceedings of the 11th Language and Development Conference, New Delhi. New Delhi: British Council.

Conteh, J. (2018.) Translanguaging as pedagogy - a critical review. In A. Creese and A. Blackledge (Eds.), The Routledge Handbook of Language and Superdiversity (pp. 473-87). London: Routledge.

Cummins, J. (2007). Rethinking monolingual instructional strategies in multilingual classrooms. The Canadian Journal of Applied Linguistics, 10(2), 221-240.

Durairajan, G. (2017). Using the First Language as a Resource in English Classrooms: What Research from India Tells us. In H. Coleman (Ed.), Multilingualisms and Development: Selected Proceedings of the 11th Language and Development Conference, New Delhi, India (pp. 307-316). London: British Council. 
García, O. (2009). Bilingual education in the 21st century: A global perspective. Malden/Oxford: Wiley/Blackwell.

García, O., \& Wei, Li. (2014). Translanguaging: Language, bilingualism and education. London: Palgrave Macmillan.

García, O., Ibarra-Johnson, S., \& Seltzer, K. (2016). The translanguaging classroom. Philadelphia: Caslon.

García, O., \& Lin, A. M. Y. (2016). Translanguaging in bilingual education. In O. García et al. (Eds.), Bilingual and Multilingual Education, Encyclopedia of Language. Switzerland: Springer International Publishing.

García, O., \& Kleyn, T. (Eds.) (2017). Translanguaging with multilingual students. New York and London: Routledge.

Hornberger, N. H., \& Link, H. (2012). Translanguaging and transnational literacies in multilingual classrooms: A bilingual lens. International Journal of Bilingual Education and Bilingualism, 15(3), 261-278.

Lewis, G., Jones, B., \& Baker, C. (2012). Translanguaging: Origins and development from school to street and beyond. Educational Research and Evaluation, 18(7), 641-654.

Lewis, G., Jones, B., \& Baker, C. (2013). 100 Bilingual lessons: Distributing two languages in classrooms'. In C. Abello-Contesse, P. Chandler, M. D. López-Jiménez, M. M. Torreblanca- López \& R. Chacón-Beltrán (Eds.), Bilingualism and Multilingualism in School Settings. Bristol: Multilingual Matters.

Li Wei. (2011). Moment analysis and translanguaging space: Discursive construction of identities by multilingual Chinese youth in Britain. Journal of Pragmatics, 43, 1222-1235.

Li Wei, \& García, O. (forthcoming). From researching translanguaging to translanguaging research. In K. King \& Yi-Ju Lai (Eds), Research Methods: Encyclopedia of Language and Education. Springer.

Lightfoot, A., Balasubramanian, A., Tsimpli, I., Mukhopadhyay, L. and Treffers-Daller, J. (in press) 'Measuring the multilingual reality: lessons from classrooms in Delhi and Hyderabad. Journal of Bilingual Education and Bilingualism.

Makalela, L. (2015). Moving out of linguistic boxes: the effects of translanguaging strategies for multilingual classrooms. Language and Education, 29(3), 200-217. https://doi.org/10.1080/09500782.2014.994524

Mathew, R., Lightfoot, A., Mukhopadhyay, L., \& Tsimpli, I. (submitted). Multilingual practices in Indian classrooms: pedagogical and policy implications for English medium contexts, In L. Adinolfi \& U. Bhattacharya (Eds.), Global lessons from multilingual education in South Asia: at the intersection of policy and practice. Routledge Publications.

Meganathan, R. (2011). Language Policy in Education and the Role of English in India: From Library Language to Language of Empowerment. In Coleman, H (Ed.), Dreams and Realities: Developing countries and the English Language. London: British Council.

Meganathan, R. (2015). Medium of Instruction in School Education in India: the policy, status and the demand for English medium education. Indian Educational Review, 53(2), 7-31.

Mukherjee, A., \& Vasanta, D. (2002). Practice and research in literacy. Research in Applied Linguistics, Vol. 5. New Delhi: Sage Publications.

Mukhopadhyay, L., Tamboli, V., Das, K., Balasubramanian, A., and Tsimpli, I. (in press). What guides inference generation? A study of young Hindi learners studying in challenging contexts in India. Indian Educational Review, NCERT Journal, India.

National Sample Survey Organisation (NSSO) (2014). India-Social Consumption - Education Survery 2014, 71 st Round. New Delhi: Ministry of Statistics and Programme Implementation, Government of India.

National Education Policy (2019). Draft, New Delhi. Retrieved from https://mhrd.gov.in/sites/upload_files/mhrd/files/Draft_NEP_2019_EN_Revised.pdf

Ortega, L. (2009). Understanding second language acquisition. New York: Routledge.

Pattanayak, D. P. (1981). Multilingualism and Mother-tongue Education. Oxford University Press.

Petrovic, J., \& Majumdar, S. (2010). Language planning for equal educational opportunity in multilingual states: the case of India. International Multilingual Research Journal, 4, 1-19.

Pratham. (2017). Annual Status of Education Report (Rural) 2016. New Delhi: Pratham. Retrieved from http://img.asercentre.org/docs/Publications/ASER\%20Reports/ASER\%202016/aser_2016.pdf 
Shepard-Carey, L. (2019). The inference-making of elementary emergent multilinguals: Access and opportunities for learning. Journal of Early Childhood Literacy, 0(0), 1-39.

Tsimpli, I., Mukhopadhyay, L., Treffers-Daller, J., Alladi, S. Marinis, T., Panda, M., Balasubramanian, A., \& Sinha, P. (2019). Multilingualism and multiliteracy in primary education in India: a discussion of some methodological challenges of an interdisciplinary research project. Research in Comparative and International Education, 14(1), 54-76. https://doi.org/10.1177/1745499919828908

Tsimpli, I., Vogelzang, M., Balasubramanian, A., Marinis, T., Alladi, S., Reddy, A., \& Panda, M. (2020). Linguistic diversity, multilingualism and cognitive skills: A study of disadvantaged children in India. Languages, 5(1).

\section{Notes}

Note 1. All the names of the teacher and students, used in this report, have been changed to maintain anonymity and permission to do classroom observation has been sought following the standards of research ethics.

Note 2. The age range of the students is wide unlike students from middle of high SES. This is because some of these children do not have a birth certificate so their parent quote an age; many others do not get admission on time due to lack of monetary resources and join school late.

Note 3. The utterances were not further classified as mono clausal, subordinating and coordinating clauses as there was no fluency analysis of the transcriptions. The utterances were analysed for their meaning and not form, unless otherwise stated.

Note 4. Glossing of the phrases in Telugu and Hindi is provided in [] brackets.

\section{Appendix}

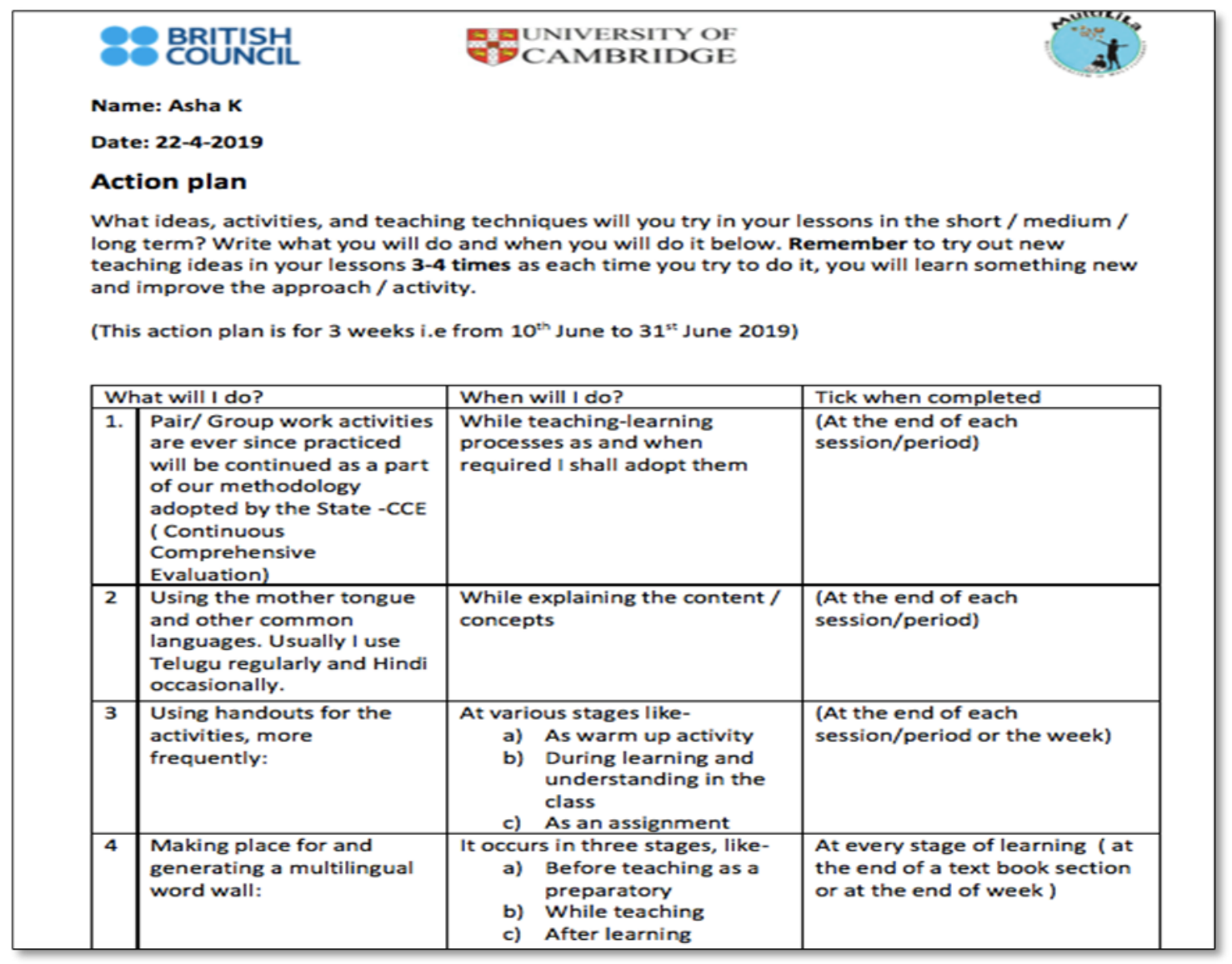




\section{Copyrights}

Copyright for this article is retained by the author(s), with first publication rights granted to the journal.

This is an open-access article distributed under the terms and conditions of the Creative Commons Attribution license (http://creativecommons.org/licenses/by/4.0/). 